\title{
A CONCEPÇÃO DE SUJEITO EM BAKHTIN
}

\section{Elizabeth Fontoura Dorneles}

Resumo: Mikhail Bakhtin, no prólogo de Marxismo e filosofia da linguagem, diz que a literatura marxista carece de uma "descrição definitiva e universalmente reconhecida da realidade específica dos problemas ideológicos" (pág.25). Mostra ainda que a ideologia é tratada, no que diz respeito aos sujeitos, como manifestação da consciência numa relação com o psiquismo, o que impede a consideração do papel da língua, como realidade material específica da criação ideológica. A proposta de analisar a concepção de sujeito que perpassa sua obra traz as considerações anteriores para o centro da discussão, uma vez que para o autor o sujeito é constituído pela palavra, que, por sua imersão no social, é ideológica. É signo carregado de significado. Na relação interindividual se constroem os objetos de pensamento, os sentidos que são portanto sociais e não efeito de um trabalho psíquico não intermediado. Anunciamos com isso três questões fundamentais para a caracterização do sujeito em Bakhtin: a ideologia, a língua e a interação entre os indivíduos.

Palavras-chave: dialogismo, ideologia, signo, sujeito e linguagem

Dialogismo e sujeito

Sempre que citamos Bakhtin nossa atenção primeira é direcionada para a literatura, pois é nesse campo que ele situa-se para tecer uma obra que hoje é reconhecida como extremamente importante para todos os que têm a linguagem como materialidade de pesquisa, sejam quais forem os sistemas de signos. É exatamente pelo signo que temos a porta aberta para fazer a ponte entre língua, ideologia e sujeito.

A relação direta do autor com a Linguística e, conseqüentemente, com o signo verbal pode começar a ser depreendida na crítica às posições estruturalistas expressas no curso de Lingüística Geral - CLG. Posições essas que acarretam orientações que expurgam o social (visão marxista) do centro dos estudos linguísticos.

(*) Mestre em Letras pela PPG/Letras UFRGS. 
Bakhtin situa nos estudos lingüísticos duas orientações distintas: o subjetivismo idealista e o objetivismo abstrato. Na crítica que tece a essas correntes, perpassa a preocupação com a concepção de língua como veículo essencial das interações sociais, as quais são mediadas pelos signos que se constituem nesse ato interindividual.

Bakhtin (1986, p.121) destaca o tratamento das questões da linguagem do eixo da filosofia idealista e as coloca sob o prisma da filosofia materialista, faz com isso a "emenda" do social ao individual na enunciação por ele assim conceituada:

A enunciação enquanto tal é um puro produto da interação social, quer se trate de um ato de fala determinada pela situação imediata ou pelo contexto mais amplo que constitui o conjunto das condições de vida de uma determinada comunidade lingüística

Pela noção de dialogismo Bakhtin mostra a ficção da separação língua / fala, quando a interação verbal é a verdadeira substância da língua. Para ele, o ato dialógico é constitutivo do sujeito social. Não há interior (pensamento) nem exterior (social) e a interação verbal se coloca como palco desse acontecimento. Na definição que dá para ato dialógico apresenta-o como todo encontro entre interlocutores. Para ele "pode-se compreender a palavra "diálogo" num sentido amplo, isto é, não apenas a comunicação em voz alta, de pessoas colocadas face a face, mas toda comunicação verbal, de qualquer tipo que seja" (idem, p.123).

As palavras ou quaisquer outros símbolos adquirem valor significante não com ênfase na cadeia, na estrutura, mas nesse terreno interindividual, onde:

É fundamental que esses dois indivíduos estejam socialmente organizados, que formem um grupo (uma unidade social): só assim um sistema de signos pode constituir-se. A consciência individual não só nada pode explicar, mas ao contrário, deve ela própria ser explicada a partir do meio ideológico e social (Idem; p. 35).

É confrontando essa afirmação do autor com as posições fundamentais da orientação "subjetivista idealista" que começamos a mostrar os fundamentos da concepção de sujeito que está presente em sua obra. 
Uma das proposições que fundamenta a tendência subjetivista é: “As leis da criação lingüística são essencialmente as leis da psicologia individual" (idem, p.72). Nessa direção encontra-se na base da criação lingüística um indivíduo cujas relações expressas pela linguagem são as estabelecidas no "mundo interior", a vida psíquica desse indivíduo onde os objetos do pensamento constituem-se, podese dizer, isolados daquilo que lhe é exterior. As leis da psicologia individual reduzem a formação de tais objetos a um trabalho biológico / psicológico onde não há espaço para o ideológico.

Bakhtin (idem, p.48) opõe-se a isso mostrando que há necessidade de uma psicologia objetiva fundamentada no social, onde a consciência é um fato sócio-ideológico, pois:

A consciência constitui um fato sócio-ideológico não acessível a métodos tomados de empréstimo à psicologia, ou às ciências naturais. É impossível reduzir o funcionamento da consciência a alguns processos que se desenvolvem no interior do campo fechado de um organismo vivo.

O organismo vivo, as estruturas neurais são o suporte biológico para que o trabalho psíquico aconteça, o qual se coloca para Bakhtin como uma reação ao que é exterior. Reconhece o autor que é nessa região limítrofe onde se dá o encontro entre o organismo e o mundo exterior que encontra-se o signo, material ideológico por essência. Bakhtin dá a psicólogos como Wilhelm Dilthey créditos por terem reconhecido que os objetos do pensamento ganham existência pela expressão simbólica, entretanto opõe-se a eles ao reivindicar que o psiquismo é uma realidade semiótica e que não há como "delimitar a fronteira entre o psiquismo subjetivo individual e a ideologia em sentido estrito" (p. 57).

Mostra, nesse sentido, que os signos não apenas expressam conteúdos do pensamento, da vida interior, como são constitutivos do próprio pensamento e que, sendo o signo ideológico, é impossível haver separação entre vida psíquica interior e a realidade exterior, o social. Afirma o autor "O signo ideológico é o território comum, tanto do psiquismo quanto da ideologia; é um território concreto, sociológico e significante". Ao fazer essa mediação entre a vida psíquica, o individual, e a ideologia, o social, pela linguagem, Bakhtin 
funda uma característica da concepção de sujeito que perpassa sua obra: um indivíduo social psico-lingüístico.

Signo e sujeito

A concepção de signo está intimamente ligada à ideologia. Afirma o autor (p.31):

Um produto ideológico faz parte de uma realidade (natural ou social) como todo o corpo físico, instrumento de produção ou produto de consumo; mas, ao contrário destes, ele também reflete e resgata uma outra realidade que lhe é exterior. Tudo que é ideológico possui um significado fora de si. Em outros termos, tudo que é ideológico é um signo. Sem signos não existe ideologia.

A passagem do objeto físico a signo se dá como processo, ou seja, o ideológico não é imanente aos instrumentos ou à própria
palavra.

O ato de instituição de um signo é social, mas com lugar para a consciência individual, pois "os signos só imergem, decididamente, do processo de interação entre uma consciência individual e outra" (p.
34 ).

Ainda que haja essa consideração ao individual, Bakhtin salienta que o terreno interindividual onde aparecem os signos não é natural, mas já está inserido no social. Dessa forma o signo banha-se no ideológico através do meio social em que nasce. Não há signo fora de um meio social e ideológico.

Com essa constatação o autor nos possibilita compreender a constituição da consciência do sujeito individual perpassado pelo social. Ela não contém em si mesma a ideologia conforme "pretendem o idealismo e o positivismo psicologizante" (p. 35). São os indivíduos organizados que, ao relacionarem-se, constituem os objetos da consciência, ou seja, simbolizam o universo, dando-lhe a forma de signos ideológicos, naturalmente, que passam a povoar o pensamento. Surge com isso uma consciência individual, mas que só ganha existência pela imersão no social, simbolizando em dois indivíduos, como já foi dito, situados num meio social e ideológico. O simbólico só se constitui através de signos que remetem à realidade, a algo que está fora, que, por sua vez, já faz parte de uma comunidade de signos. 
A cadeia significante que em Saussure (CLG 142-147) adquire valor no interior da própria estrutura, pelas relações que se estabelecem no sintagma e pelas associações entre objetos do pensamento, em Bakhtin, constitui-se numa relação social interindividual intermediada pelos signos.

Interessante destacar que os objetos materiais ou lingüísticos transformam-se em signos ao apontarem para algo que já instituiu-se como realidade, que possui uma materialidade social particular que se "reflete" e será refratada em outros signos. Essa é a cadeia significante através da qual a ideologia vai constituindo signos e constituindo-se. $\mathrm{Da}$ mesma forma que a consciência individual imerge como um fato sócio- ideológico.

Ao explicitar-se que o signo é o suporte da ideologia em Bakhtin, bem como que as relações interindividuais, mediadas por signos, constituem a consciência individual, torna-se possível estabelecer semelhanças entre essa "consciência individual" - sujeito e o sujeito da AD.

Nessa perspectiva, poderíamos fazer a aproximação tanto pelo viés da ideologia, pela tese althusseriana: "A ideologia interpela os indivíduos em sujeito" quanto pela presença da linguagem na interpelação ideológica proposta e teorizada por Pêcheux.

Ainda que mantidas as devidas distinções conceituais, é possível aproximações, Já que ideologia e linguagem em Bakhtin e Pêcheux são constitutivas do sujeito, colocam em contato "interior e exterior".

Em Bakhtin, a ideologia está no signo, se materializa na linguagem que, pela interação interindividual, constitui o sujeito consciente mas não autônomo, porque seu pensamento se forma como efeito da imersão num mundo de signos instituídos nas relações estabelecidas entre indivíduos situados em lugares sociais historicamente dados. São os signos que dão materialidade para o pensamento interior e possibilidade da veiculação dos sentidos instituidores desse sujeito ideológico. Nesse jogo o signo reflete a realidade, dá concretude à ideologia que perpassa as relações de produção numa determinada formação social.

Em Pêcheux (1995), a relação entre pensamento e realidade / anterioridade se dá pelo encaixamento do pré-construído, que articula- 
se com uma nova realidade materializada pela linguagem e que, desde uma formação discursiva dada, "chama" o sujeito e faz com que ele se identifique com determinada posição-sujeito, e ali constitua-se como sujeito, desde sempre sujeito.

Nesse processo, a ideologia opera e produz a ilusão de acobertamento entre o pré-construído, os objetos de pensamento já constituídos, e o novo, aquilo que encaixa-se através de mecanismos lingüísticos que podem simular o apagamento da "costura" que uniu interior e exterior. É então nesse processo sócio-histórico que se constitui-reproduz o efeito-sujeito como interior sem exterior, e isso pela determinação do real (exterior), e especificamente acrescentaremos do interdiscurso como real (exterior) (p. 163).

Nos dois filósofos de orientação marxista, a linguagem, o signo, é deslocada do lugar de objeto neutro que serve para expressar relações lógicas entre realidade e pensamento e é colocada, num jogo duplo, como constituída / constituidora da ideologia, do pensamento, do próprio sujeito.

Andam por caminhos diferentes para construírem a crítica. Bakhtin questiona o subjetivismo individualista e insere o social e a ideologia na linguagem que, por sua vez, são conectados ao pensamento pelos signos. Pêcheux, do interior da própria Linguiística, tece a crítica mostrando a impossibilidade de a Semântica ser tratada sem que Filosofia e Lingüística sejam reconhecidas como formadoras de uma unidade teórica que dê conta da análise das formações sociais e de sua inserção no lingüístico, da análise dos mecanismos que materializam o ideológico no simbólico. Pêcheux chega assim ao discurso onde sentido e sujeito são efeitos de processos afetados pelo ideológico incidindo na linguagem. É o ideológico que dá materialidade histórica ao linguiístico, tanto em Bakhtin quanto em Pêcheux.

Sujeito e discurso

Bakhtin, em Problemas da Poética de Dostoiévski, ao tratar sobre o discurso, traz para o centro a questão do sujeito e das relações dialógicas no discurso. É importante dizer desde já que Bakhtin explicita sua concepção de discurso como a língua viva. Diz ele que o discurso é "a língua em sua integridade concreta e viva e não a língua como objeto específico da linguística". A língua só pode ter vida, 
como mostra o próprio autor, pelo ato da enunciação, logo sujeito e língua estão implicados no discurso.

No texto citado evidencia-se ainda mais esse sujeito como ser individual que pode contrapor-se a outro através de enunciados. Essa é a relação dialógica original, onde cada indivíduo assume a autoria de relações lógicas concreto-semânticas que tornam-se discurso pelo fato de que são enunciadas por sujeitos que, por tal ato, criam posições. Diz o autor:

Todo enunciado tem uma espécie de autor, que no próprio enunciado escutamos como seu criador. Podemos não saber absolutamente nada sobre o autor real , como ele existe fora do enunciado. As formas dessa autoria real podem ser muito diversas. Uma obra qualquer pode ser produto de um trabalho de equipe, pode ser interpretado como trabalho hereditário de várias gerações, e apesar de tudo, sentimos nela uma vontade criativa única, uma posição determinada diante da qual se pode reagir dialogicamente. A reação dialógica personifica toda enunciação à qual ela reage (Bakhtin; 1981, p.159)

A relação dialógica dá à língua materialidade discursiva, pois aquilo que é da ordem da realidade, ao ser enunciado por "indivíduos socialmente organizados", faz com que as palavras enunciadas adquiram o estatuto de signo, ou seja: a língua banha-se no ideológico no ato da enunciação, por essência dialógica. Podemos ir além e dizer que as relações lógicas historicizam-se e aí então constituem-se diferentes posições, cuja origem são sujeitos. Os dados da realidade ao serem simbolizados, ganham materialidade ideológica. A língua fica fecundada pelo social, representado pelos sujeitos que a tomam e constroem signos, organizam-nos dando-lhes estrutura concretosemântico, naturalmente ideológica.

$\mathrm{Na}$ citação, Bakhtin nos mostra que na enunciação o autor pode se constituir como aquele que reúne, que organiza o já dito, entretanto ele se apresenta como o sujeito dotado de intenção que, pela dialogia, faz saber de si, personifica-se e institui novos signos, uma vez que eles só têm existência "no processo de interação entre uma consciência individual e outra". 
O modo como a interação entre esses sujeitos individuais, conscientes e ideológicos se dá, pode ser tratado a partir dos gêneros do discurso. Bakhtin (1977; p.279-326) mostra que os signos constituem enunciados primários organizados de acordo com a intencionalidade do sujeito. Desse modo classifica como discurso primário as formas naturais usadas nas relações dialógicas, ou seja: pergunta, réplica, asserções, carta, bilhete. Esses enunciados são os elementos componenciais de uma segunda categoria de discurso que denomina de discurso secundário. Essa última corresponde aos textos já elaborados nos quais o discurso primário está presente, mas com estilo próprio ao autor que insere as perguntas, réplicas, asserções e outros no romance. As duas categorias constituem o que denomina os gêneros do discurso.

Os enunciados relativos aos gêneros primários apresentam-se como a possibilidade de formalização do pensamento do sujeito frente a outro sujeito e também como uma estrutura que submete-se ao estilo dos sujeitos e possibilita a demarcação da presença dos mesmos. Essa individualização se dá no processo dialógico onde há uma espécie de negociação entre aquilo que se coloca como a estrutura, os gêneros primários, e o estilo individual, os gêneros secundários.

O sujeito, através do estilo, marca sua presença na enunciação. Ele usa o enunciado de modo individual, pois toma a estrutura, os gêneros primários, e a organiza num estilo próprio. Com isso vai entrando sempre nos enunciados padronizados e os reabilitando por esse movimento dialógico entre os gêneros. Desse modo o discurso está preso ao sujeito e ganha estilo, características próprias a partir do ato dialógico.

Considerações finais

A noção de sujeito em Bakhtin está diretamente ligada à ideologia, ao signo e ao enunciado. Nessa característica há convergência com a Análise do Discurso AD. Entretanto a distinção entre as duas posições se estabelece já no interior da concepção de sujeito.

Bakhtin concebe o sujeito com efeito do social mas é coincidente com a noção de indivíduo, de ser empírico. O social que o constitui interfere na formação dos objetos do pensamento, mas o mantém uno, indivisível e senhor de si mesmo. O próprio dialogismo 
se estabelece a partir de uma relação jurídica entre dois indivíduos responsáveis pelo conteúdo, pelo estilo dos seus dizeres e pela interação, pela consideração ao outro. A atitude responsiva que se estabelece entre os interlocutores está marcada por fatores indissociáveis ligadas ao enunciado. Entre eles um trata sobre a intencionalidade do locutor. Nesse caso, o intuito do locutor corresponde ao de um sujeito consciente e é considerado o elemento subjetivo do enunciado que entra em contato com o elemento objetivo, objeto do sentido, para formarem uma unidade indissolúvel de comunicação verbal.

A ideológica se materializa nos signos que só têm existência pela relação interindividual estabelecida entre sujeitos situados, socialmente constituídos. Nesse sentido podemos dizer que o sujeito é consciente, mas não autônomo. O sentido que o sujeito dá, os signos que constituem a consciência individual, está revestido de valor ideológico. Não há sujeito fora da ideologia e da linguagem nem em Bakhtin, nem em AD. O que diferencia profundamente as concepções de sujeito nas duas correntes de abordagem da linguagem são as formações imaginárias que, no caso da $\mathrm{AD}$, atravessam um sujeito não-centrado, não-consciente. 
Referências

BAKHTIN, Mikhail. Marxismo e Filosofia da Linguagem. 3. ed. São Paulo: HUCITC, 1986

BAKHTIN, Mikhail. Problemas da Poética de Dostoievski. Rio de Janeiro: Forense Universitária, 1981

BAKHTIN, Mikhail. Estética da criação verbal. 2. ed. São Paulo: Martins Fontes, 1997

PÊCHEUX, Michel. Semântica e discurso: uma crítica a afirmação do óbvio. 2ed. Campinas: Editora da Unicamp, 1995

SAUSSURE, Ferdinand. Curso de Lingüística Geral. 20. ed. São Paulo: Cultrix, 1995 